\title{
Cardiovascular Damage in Alzheimer Disease: Autopsy Findings From the Bryan ADRC
}

\author{
Elizabeth H. Corder, ${ }^{1}$ John F. Ervin, ${ }^{2}$ Evelyn Lockhart, ${ }^{3}$ Mari H. Szymanski, ${ }^{2}$ \\ Donald E. Schmechel, ${ }^{3,4}$ and Christine M. Hulette ${ }^{2,3}$ \\ ${ }^{1}$ Center for Demographic Studies, Duke University, 2117 Campus Drive, Box 90408, Durham, NC 27708-0408, USA \\ ${ }^{2}$ Division of Neurology, Duke University Medical Center, Durham, NC 27710, USA \\ ${ }^{3}$ Department of Pathology, Duke University Medical Center, Durham, NC 27710, USA \\ ${ }^{4}$ Department of Neurobiology, Duke University Medical Center, Durham, NC 27710, USA
}

Received 7 June 2004; revised 29 November 2004; accepted 7 December 2004

\begin{abstract}
Autopsy information on cardiovascular damage was investigated for pathologically confirmed Alzheimer disease (AD) patients $(n=84)$ and non-AD control patients $(n=60)$. The 51 relevant items were entered into a grade-of-membership model to describe vascular damage in AD. Five latent groups were identified "I: early-onset AD," "II: controls, cancer," "III: controls, extensive atherosclerosis," "IV: late-onset $\mathrm{AD}$, male," and "V: late-onset $\mathrm{AD}$, female." Expectedly, Groups IV and V had elevated APOE $\epsilon 4$ frequency. Unexpectedly, there was limited atherosclerosis and frequent myocardial valve and ventricular damage. The findings do not indicate a strong relationship between atherosclerosis and $\mathrm{AD}$, although both are associated with the APOE $\epsilon 4$. Instead, autopsy findings of extensive atherosclerosis were associated with possible, not probable or definite $\mathrm{AD}$, and premature death. They are consistent with the hypothesis that brain hypoperfusion contributes to dementia, possibly to AD pathogenesis, and raise the possibility that the $A P O E$ allele $\epsilon 4$ contributes directly to heart valve and myocardial damage.
\end{abstract}

\section{INTRODUCTION}

It is well known that Alzheimer's disease (AD) is the most common form of senile dementia in the US and Europe. Population studies suggest that $47 \%$ of persons over age 85 are affected $[1,2,3]$. The established genetic risk factor is the $\mathrm{E} 4$ isoform for the lipid transport molecule apolipoprotein E (APOE: gene; ApoE: protein) $[4,5,6,7,8,9,10]$ which is also a risk factor for coronary atherosclerosis $[11,12,13,14,15,16,17,18,19]$. The $\epsilon 4$ allele for $A P O E$ has sometimes been implicated in vascular dementia $(\mathrm{VaD})$ and stroke $[20,21,22]$, the second most common form of senile dementia.

Previous studies have shown decreased smooth muscle actin in brain blood vessels of $\mathrm{AD}$ patients when compared to nondemented controls [23]. Possibly, more extensive amyloid deposition in heart and brain vessels determines the 5 -fold worse prognosis ( $8 \%$ compared to

Correspondence and reprint requests to Christine M. Hulette, Soybean Genomics and Improvement Laboratory, USDA-ARS, Beltsville, MD 20705, USA, E-mail: hulet001@mc.duke.edu

This is an open access article distributed under the Creative Commons Attribution License which permits unrestricted use, distribution, and reproduction in any medium, provided the original work is properly cited.
$40 \%$ mortality) within three months following a diagnosis of heart disease or stroke at ages $85+$ for $\epsilon 3 / 4+$ persons, compared to $\epsilon 2 / 3+[24]$, and largely accounts for reduced $\epsilon 4$, and elevated $\epsilon 2$, frequencies found among centenarians [25].

The role of cardiovascular damage in the development of $\mathrm{AD}$ is consistent with a number of existing reports in the literature, although few deal with pathologically confirmed $\mathrm{AD}$ and pathologic cardiovascular findings in age-matched samples. Certainly, cardiovascular damage is common among subjects with neuropathologically confirmed AD [26, 27]. Hypertension has been suggested as a risk factor for subsequent $\mathrm{AD}$, normal or low blood pressure at the end stages of the disease [28, 29, 30, 31, 32]. Skoog et al [31] investigated a population cohort and found an association between elevated blood pressure at age 70 years and the development of dementia 10 to 15 years later. They hypothesized that hypertension causes hyalinization of the vessel walls in the brain and hypoperfusion in the deep white matter.

Atherosclerotic disease and silent myocardial infarcts have been associated with cognitive impairment $[26,27]$. In the Rotterdam study [33], the extent of atherosclerosis was assessed by ultrasonography of the carotid arteries and by the ratio of ankle to brachial systolic blood pressure. Subjects were scored from 0 to 3 , from no to severe, atherosclerosis. The odds of a clinical $\mathrm{AD}$ diagnosis 
increased 2-fold with the extent of atherosclerosis, 3-fold for $\mathrm{VaD}$.

Autopsy studies are limited, but suggest that cardiovascular disease contributes to the expression of dementia for patients who exhibit Alzheimer neuropathologic changes. Sparks et al [28] showed that significant coronary artery disease was present in 90\% (19 of 21) of $\mathrm{AD}$ patients undergoing a complete postmortem examination. Patients with peripheral vascular disease, cerebrovascular accidents, and myocardial infarcts had lower antemortem cognitive scores on the minimental state exam [27]. Patients with end-stage renal disease have cognitive impairment thought to be due to multiinfarct dementia [34].

However, Irina et al [35] did not find a correlation of dementia or pathologically confirmed $\mathrm{AD}$ with pathologic cardiovascular index (CVI), that is, the extent of atherosclerosis in the brain and periphery combined with evidence of cardiovascular lesions and cardiomegaly. Specifically, the CVI was higher for 103 nondemented subjects compared to 106 demented subjects, 9.2 versus 7.5 out of a possible $15(P<.05)$. Mean CVI was 5.2 for subjects meeting CERAD criteria for possible $\mathrm{AD}, 7.3$ for definite $\mathrm{AD}$, increasing to 8.5 for vascular and mixed dementia. Thus atherosclerosis was associated with $\mathrm{VaD}$, not the extent of Alzheimer's lesions (associated with the $\epsilon 4$ allele for $A P O E)$.

To clarify the role of cardiovascular disease in dementia, we investigated 144 subjects prospectively enrolled in the Bryan Alzheimer Disease Research Center Rapid Autopsy Program at Duke University who had had complete body autopsies.

\section{METHODS}

\section{The rapid autopsy program}

The Rapid Autopsy Program of the Bryan Alzheimer Disease Research Center has been in continuous existence since 1985 [36]. Recruitment, enrollment, and autopsy procedures have been approved by the Institutional Review Board. After receiving informed consent from the patients and their families, both demented and nondemented control donors are enrolled and followed prospectively until death. While the principal purpose of the program is to retrieve and bank human brain tissue for use in research, many donors have consented to complete diagnostic autopsy. At the time of death, consent for autopsy is again obtained according to Duke University Medical Center regulations. Autopsy is performed in the usual fashion with examination of all body organs and cavities. Autopsies are performed in compliance with Centers for Disease Control precautions against the spread of infectious diseases $[37,38]$.

\section{Data abstraction}

APOE genotype (for 46 demented and 38 nondemented subjects) was obtained from existing databases.
We abstracted the 144 autopsy records to obtain information on dementia status, cardiovascular disease, medical diagnoses, and organ weights. An Excel spreadsheet was used as the abstract form. Abstraction was done independently by two persons. Inconsistencies were resolved by consensus among the authors. The 51 items are listed in Tables $1-3$, respectively.

\section{The statistical approach}

Detailed clinical profiles were identified using a statistical technique called grade-of-membership analysis or GoM $[39,40]$. Use of univariate approaches would necessarily have low power at this sample size, especially if corrected for multiple comparisons (not needed when all variables are jointly examined). An additional advantage is that each variable can be understood in relation to all the other variables allowing a clinical narrative, something like the process of diagnosis, to be achieved for the identified latent model-based groups.

GoM can be described after first identifying four indices. One is the number of subjects $I(i=1,2, \ldots, I)$. Here $I=144$ subjects were identified. The second index is the number of variables $J(j=1,2, \ldots, J)$. There are $J=50$ variables each representing one of the clinical variables described above. Our third index is $L j$ : the set of response levels for the $J$ th variable.

This leads to the definition of the basic GoM model where the probability that the $i$ th subject has the $L j$ th level of the $J$ th variable is defined by a binary variable (ie, $y_{i j l}=$ $0,1)$. The model with these definitions is

$$
\operatorname{Prob}\left(y_{i j l}=1.0\right)=\sum_{k} g_{i k} \lambda_{k j l}
$$

where the $g_{i k}$ are convexly constrained scores (ie, $0.0 \leq$ $g_{i k} \leq 1.0 ; \sum_{k} g_{i k}=1.0$ ) for subjects and the $\lambda_{k j l}$ are probabilities that, for the $K$ th latent group, the $L j$ th level is found for the $J$ th variable. The procedure thus uses this expression to identify $K$ profiles representing the pattern of $J \times L j$ responses found for $I$ subjects.

The parameters $g_{i k}$ and $\lambda_{k j l}$ are estimated simultaneously using the likelihood function (in its most basic form) $[39,40]$.

$$
L=\prod_{i} \prod_{j} \prod_{l}\left(\sum_{k} g_{i k} \cdot \lambda_{k j l}\right)^{y_{i j l}} .
$$

In the likelihood $y_{i j l}$ is 1.0 if the $L j$ th level is present and 0.0 if it is not present. GoM models specifying from $K=3-5$ groups, that is, clinical profiles, were constructed. The significance of adding the $K+1$ profile was tested as an independent increment in the fit of the model adjusting for the larger number of degrees of freedom in the larger model. Akaike information criterion [41] was calculated as

$$
\mathrm{AIC}=-2 l(\hat{\theta})+2 P,
$$


TABLE 1 . The clinical variables.

\begin{tabular}{lll}
\hline No & Variable & Description \\
\hline 1 & Dementia & $0=$ no, $1=$ yes (ie, age at onset listed) \\
& $0=$ normal, $1=$ dementia, $2=$ normal cognition, \\
& Dementia status & $3=$ disease control, $4=$ early dementia, \\
& $6=$ Parkinson's disease $(\mathrm{PD})$ \\
3 & Final diagnosis & $0=$ normal, $1=\mathrm{AD}, 2=\mathrm{PD}, 3=$ possible AD, $4=$ not listed \\
4 & Age at onset & $0=$ not demented, $1 \leq 60$ years of age, $2=60-70,3=70-80,4=80+$ \\
5 & Duration of dementia & $0=$ normal, $1 \leq 5$ years, $2=5-10,3=10-15,4=15+$ \\
6 & Age at death & $1 \leq 60$ years, $2=60-70,3=70-80,4=80+$ \\
7 & Sex & $0=$ male, $1=$ female \\
8 & Race & $0=$ white, $1=$ black \\
9 & Body mass index & $0=8-17.9,1=17.9-21.2,2=21.2-25.0,3=25+, 9=$ missing \\
10 & Cancer diagnosis & $0=$ no, $1=$ yes \\
11 & Respiratory system infection & $0=$ no, $1=$ yes \\
12 & Urinary system infection & $0=$ no, $1=$ yes \\
13 & Digestive system infection & $0=$ no, $1=$ yes \\
14 & APOE genotype & $0=\epsilon 22,1=\epsilon 23,2=\epsilon 33,3=\epsilon 24,4=\epsilon 34,5=\epsilon 44$ \\
\hline
\end{tabular}

where $l$ is the likelihood value and $P$ is the number of estimated parameters. However, for parameters on the boundary, that is, value $=0$, only one is penalized. The rationale for subtracting only one for parameters on the boundary is that the distribution for those parameters is $(1 / 2) X^{2}$ (central). The lowest value of the AIC designates the best model, that is, the model with the best fit and least bias. GoM models specifying either 3, 4, 5, or 6 clinical profiles, that is, $K=3-6$, had AIC = $-1503,-1647,-1703$, and -1678 , respectively. The 5group model is reported.

Information on $A P O E$ genotype was not used to construct the groups used to clinically characterize the subjects. One option in the likelihood is to separate calculations for "internal" (here, clinical) and "external" (here, APOE genotype) variables. For internal variables, MLE of $g_{i k}$ and $\lambda_{k j l}$ are generated and the information in internal variables is used to define the $K$ groups. For external variables the likelihood is evaluated (and MLE of $\lambda_{k j l}$; generated) but the information is not used to redefine the $K$ groups, that is, the likelihood calculations for likelihood equations involving the $g_{i k}$ are disabled for external variables so that the $g_{i k}$, and the definition of the $K$ groups, is not changed.

\section{RESULTS \\ Overview}

Five model-based groups best represented the autopsy information on diagnoses, cardiovascular disease, and organ weights. They are labeled I, II, III, IV, and V ordered according to increasing age at the time of death. Each group is defined by the probabilities of response for the many variables, akin to the frequencies found in the sample as a whole. Tables $4-6$ describe the profiles in terms of diagnoses, cardiovascular damage, and organ weights, respectively. Not all the variables described in Tables 1-3 are shown in the tables of results.

The size of the groups was similar (Table 4). The sizes are the summed memberships of individuals in the respective groups either partial, that is, fractional, or complete, that is, contributing size one to the sum, depending on the extent of resemblance of the individual to the group. Group I was the largest group $(n=36.4)$ and Group II was the smallest $(n=21.3)$. The prevalence of demented and nondemented subjects, that is, sum of memberships, in each model-based group is shown in Table 7, as well as the distribution of APOE frequencies across the model-based groups.

\section{Dementia diagnoses}

Next observe that the groups were either demented or not demented (Table 4): Groups I, IV, and V had 100\% probability of dementia while Groups II and III were not demented. There was high probability that dementia was specifically due to AD: $81 \%$ for Group I, 73\% for Group IV, and $72 \%$ for Group V. Otherwise, no explanatory diagnosis was given for the dementia for these groups. Groups II and III had no chance of an AD diagnosis. However, possible $\mathrm{AD}$ was sometimes found in the nondemented groups, 9\% for Group II and 43\% for Group III (5-10 years younger than Groups IV and V). Group II had a $22 \%$ chance of being a so-called "disease control" and Group III had a 10\% chance of having Parkinson's disease. The dementia status and final diagnoses variables are described in Table 2.

\section{Onset age, sex, and dementia duration}

As the age at the onset of dementia for Group I was usually before age 65, Group I represents early-onset AD. Groups IV (male) and V (female) represent late- 
TABLE 2. The cardiovascular variables.

\begin{tabular}{|c|c|c|}
\hline No & Variable & Description \\
\hline 15 & Pericardial cavity fluid & $0 \leq 10 \mathrm{~mL}, 1=11-50,2=51-100,3 \geq 100,9=$ missing \\
\hline 16 & Right pleural cavity fluid & $0 \leq 10 \mathrm{~mL}, 1=11-50,2=51-100,3 \geq 100,9=$ missing \\
\hline 17 & Left pleural cavity fluid & $0 \leq 50 \mathrm{~mL}, 1=51-200,2=201-500,3 \geq 500,9=$ missing \\
\hline 18 & Peritonial fluid & $0 \leq 50 \mathrm{~mL}, 1=51-200,2=201-500,3 \geq 500,9=$ missing \\
\hline 19 & Aorta atherosclerosis & $0=$ normal, $1=$ mild, $2=$ moderate, $3=$ severe, $9=$ missing \\
\hline 20 & Right coronary artery atherosclerosis & $0=$ normal, $1=$ mild, $2=$ moderate, $3=$ severe, $9=$ missing \\
\hline 21 & Right coronary artery narrowing & $0=$ normal, $1=5 \%-25 \%, 2=26 \%-75 \%, 3 \geq 75 \%, 9=\operatorname{missing}$ \\
\hline 22 & Right coronary artery calcification & $0=$ normal, $1=$ mild, $2=$ moderate, $3=$ severe, $9=$ missing \\
\hline 23 & Left main coronary artery atherosclerosis & $0=$ normal, $1=$ mild, $2=$ moderate, $3=$ severe, $9=$ missing \\
\hline 24 & Left main coronary artery narrowing & $0=$ normal, $1=5 \%-25 \%, 2=26 \%-75 \%, 3 \geq 75 \%, 9=\operatorname{missing}$ \\
\hline 25 & Left main coronary artery calcification & $0=$ normal, $1=$ mild, $2=$ moderate, $3=$ severe, $9=$ missing \\
\hline 26 & Circumflex branch atherosclerosis & $0=$ normal, $1=$ mild, $2=$ moderate, $3=$ severe, $9=$ missing \\
\hline 27 & Circumflex branch narrowing & $0=$ normal, $1=5 \%-25 \%, 2=26 \%-75 \%, 3 \geq 75 \%, 9=$ missing \\
\hline 28 & Circumflex branch calcification & $0=$ normal, $1=$ mild, $2=$ moderate, $3=$ severe, $9=$ missing \\
\hline 29 & Anterior descending branch atherosclerosis & $0=$ normal, $1=$ mild, $2=$ moderate, $3=$ severe, $9=$ missing \\
\hline 30 & Anterior descending branch narrowing & $0=$ normal, $1=5 \%-25 \%, 2=26 \%-75 \%, 3 \geq 75 \%, 9=\operatorname{missing}$ \\
\hline 31 & Anterior descending branch calcification & $0=$ normal, $1=$ mild, $2=$ moderate, $3=$ severe, $9=$ missing \\
\hline 32 & Right atrial cavity dilation & $0=$ normal, $1=$ mild, $2=$ moderate, $3=$ severe, $9=$ missing \\
\hline 33 & Right atrial wall thickness & $0=$ normal, $1=$ mild, $2=$ moderate, $3=$ severe, $9=$ missing \\
\hline 34 & Right ventricular cavity dilation & $0=$ normal, $1=$ mild, $2=$ moderate, $3=$ severe, $9=$ missing \\
\hline 35 & Right ventricular wall thickness & $0=$ normal, $1=$ mild, $2=$ moderate, $3=$ severe, $9=$ missing \\
\hline 36 & Left atrial cavity dilation & $0=$ normal, $1=$ mild, $2=$ moderate, $3=$ severe, $9=$ missing \\
\hline 37 & Left atrial wall thickness & $0=$ normal, $1=$ mild, $2=$ moderate, $3=$ severe, $9=$ missing \\
\hline 38 & Right ventricular cavity dilation & $0=$ normal, $1=$ mild, $2=$ moderate, $3=$ severe, $9=$ missing \\
\hline 39 & Right ventricular wall thickness & $0=$ normal, $1=$ mild, $2=$ moderate, $3=$ severe, $9=$ missing \\
\hline 40 & Aortic valve & $0=$ normal, $1=$ abnormal, $9=$ missing \\
\hline 41 & Tricuspid valve & $0=$ normal, $1=$ abnormal, $9=$ missing \\
\hline 42 & Pulmonic valve & $0=$ normal, $1=$ abnormal, $9=$ missing \\
\hline 43 & Mitral valve & $0=$ normal, $1=$ abnormal, $9=$ missing \\
\hline 44 & Ventricular myocardium & $0=$ normal, $1=$ abnormal, $9=$ missing \\
\hline
\end{tabular}

TABLE 3. The quartiles for organ weights.

\begin{tabular}{lll}
\hline No & Variable & Description \\
\hline 45 & Heart & $0 \leq 295 \mathrm{gm}, 1=295-351,2=351-412,3=412+, 9=$ missing \\
46 & Lungs (mean) & $0 \leq 316 \mathrm{gm}, 1=316-443,2=443-585,3=585+, 9=$ missing \\
47 & Liver & $0 \leq 880 \mathrm{gm}, 1=880-1100,2=1100-1140,3=1140+, 9=$ missing \\
48 & Kidneys (mean) & $0 \leq 99 \mathrm{gm}, 1=99-125,2=125-153,3=153+, 9=$ missing \\
49 & Spleen & $0 \leq 75 \mathrm{gm}, 1=75-113,2=113-170,3=170+, 9=$ missing \\
50 & Adrenals (mean) & $0 \leq 6.95 \mathrm{gm}, 1=6.95-8.1,2=8.1-10.2,3=10.2+, 9=$ missing \\
51 & Thyroid & $0 \leq 9.25 \mathrm{gm}, 1=9.25-14,2=14-20,3=20+, 9=$ missing \\
\hline
\end{tabular}

onset $\mathrm{AD}$ : the mean age at onset was around 70 years of age for both groups, marginally earlier for female Group V compared to male Group IV. Nonetheless Group $\mathrm{V}$ had longer disease duration and an older age at the time of death. The $2 \%$ of the sample that was black was concentrated in the control Groups II and III (not shown).

\section{BMI and nonneurologic diagnoses}

Early-onset dementia (I) was associated with extremely low body mass index (BMI). Women with lateonset dementia and long dementia duration (V) also had very BMI. Cancer was a common diagnosis for Group II, absent for Group III. Men with late onset dementia also frequently had cancer (IV), absent for female Group V. 
TABLE 4. Clinical variable frequencies for each group. Each model-based group is defined by the probabilities of being demented \& probabilities of response for the other variables, that is, the model $\lambda$ parameters.

\begin{tabular}{|c|c|c|c|c|c|c|}
\hline \multirow{3}{*}{ Variable } & \multirow{3}{*}{ Response } & \multicolumn{5}{|c|}{ Group } \\
\hline & & $N=36.4$ & $N=21.3$ & $N=27.2$ & $N=27.5$ & $N=31.5$ \\
\hline & & I & II & III & IV & $\mathrm{V}$ \\
\hline Demented & Yes $(\%)$ & 100 & 0 & 0 & 100 & 100 \\
\hline \multirow{4}{*}{ Age at onset } & $<60$ years & 81 & - & - & 7 & 0 \\
\hline & $60-70$ & 15 & - & - & 35 & 53 \\
\hline & $70-80$ & 4 & - & - & 46 & 34 \\
\hline & $80+$ & 0 & - & - & 12 & 13 \\
\hline \multirow{4}{*}{ Duration of dementia } & $<5$ years & 12 & - & - & 5 & 0 \\
\hline & $5-10$ & 38 & - & - & 62 & 0 \\
\hline & $10-15$ & 43 & - & - & 33 & 37 \\
\hline & $15+$ & 7 & 一 & - & 0 & 63 \\
\hline \multirow{4}{*}{ Age at death } & $<60$ & 20 & 20 & 0 & 0 & 0 \\
\hline & $60-70$ & 73 & 0 & 12 & 0 & 0 \\
\hline & $70-80$ & 7 & 73 & 68 & 31 & 12 \\
\hline & $80+$ & 0 & 7 & 20 & 69 & 88 \\
\hline Sex & Female & 66 & 20 & 35 & 0 & 100 \\
\hline \multirow{4}{*}{$\operatorname{BMI}\left(\mathrm{km} / \mathrm{m}^{2}\right)$} & $8-17.9$ & 67 & 0 & 0 & 4 & 23 \\
\hline & $17.9-21.2$ & 11 & 0 & 0 & 37 & 54 \\
\hline & $21.2-25.0$ & 13 & 41 & 17 & 51 & 14 \\
\hline & $25+$ & 10 & 59 & 83 & 9 & 9 \\
\hline Cancer diagnosis & Yes & 24 & 84 & 0 & 60 & 0 \\
\hline Respiratory infection & Yes & 69 & 70 & 82 & 57 & 100 \\
\hline Urinary tract infection & Yes & 16 & 16 & 27 & 29 & 44 \\
\hline Digestive tract infection & Yes & 20 & 0 & 22 & 30 & 54 \\
\hline
\end{tabular}

Respiratory and urinary infections were common for each group especially for demented women (V). Digestive tract infections were not found for Group II (cancer).

\section{Cardiovascular disease}

There was little evidence of cardiovascular disease for the early-onset relatively young Group I. Control Group II with cancer uniquely often had pulmonary effusions, ascites, and a moderately dilated right ventricle. Groups II-V had minimal amounts of pericardial cavity fluid, absent for Group I (not shown).

Control Group III without cancer had severe atherosclerosis with narrowing and calcification in the aorta and each of the major coronary vessels - right coronary artery, left main coronary artery, circumflex branch, and anterior descending branch. The extent of athersclerosis was usually similar for each vessel. Table 5 represents the average over all the coronary vessels. Group III with extensive atherosclerosis often also had moderate atrial dilation and moderately thickened ventricular myocardium (not shown).

Atherosclerosis was unexpectedly less extensive for demented Groups IV and V, limited for Group II, and absent for Group I.
Aortic and mitral valve damage and evidence of ischemic damage to the left ventricular myocardium were common for male late-onset dementia Group IV, and also female Group V. Both of the late-onset dementia groups and Group III had a moderately dilated right atrium.

\section{Organ weights}

Generally speaking, the organ weights shown in Table 6 paralleled the BMI results shown in Table 4 . Nonetheless there were some interesting departures: organ weights were preserved for Group I having the lowest BMI. The low heart weight for this relatively young group is consistent with limited heart damage, as indicated by Table 4. Lung weight was highest for Group II, which often had pulmonary edema and pleural effusions. Group III, most affected by atherosclerosis, had the highest heart weight. Compared to Group III, organ weights and BMI were lower for Group IV. Very low BMI and weight for most organs was found for late-onset dementia Group V, females with long dementia duration. Notably, both lateonset dementia groups had low thyroid weight compared to the early-onset and control groups. 
TABle 5. Cardiovascular damage for each group. The model-based groups are defined by the probabilities response for the variables sometimes represented on a semiquantitative scale: "+ ++" denotes severe, while ",++ , "+," and "- " denote moderate, mild, and the absence of lesions; "+ + /-" denotes mixture of moderate and absent; “+/-" denotes mixture of mild and absent; "+ +/+" denotes a mixture of moderate and mild; " $+++/-$ ” denotes a mixture of severe and absent. * means the average of right coronary artery, left main coronary artery, circumflex branch, and anterior descending branch.

\begin{tabular}{|c|c|c|c|c|c|c|}
\hline \multirow{2}{*}{ Outcome } & \multirow{2}{*}{ Location } & \multicolumn{5}{|c|}{ Group } \\
\hline & & I & II & III & IV & $\mathrm{V}$ \\
\hline \multirow{2}{*}{ Fluid } & Peritoneal cavity & - & $+++/-$ & $+/-$ & - & - \\
\hline & Pleural cavity & - & +++ & $+/-$ & - & - \\
\hline \multirow{3}{*}{ Coronary artery* } & Atherosclerosis & - & $+/-$ & +++ & ++ & + \\
\hline & Narrowing & - & $+/-$ & +++ & ++ & + \\
\hline & Calcification & - & $+/-$ & +++ & ++ & + \\
\hline Aorta & Atherosclerosis & $+/-$ & ++ & +++ & ++ & $++/+$ \\
\hline \multirow{4}{*}{ Dilation } & Right atrium & - & $+/-$ & $++/-$ & ++ & ++ \\
\hline & Right ventricle & $+/-$ & $++/-$ & $+/-$ & + & + \\
\hline & Left atrium & - & $+/-$ & $+/-$ & $+/-$ & $+/-$ \\
\hline & Left ventricle & $+/-$ & + & + & - & $+/-$ \\
\hline \multirow{5}{*}{ Damage } & Aortic valve & - & 20 & - & 100 & 33 \\
\hline & Mitral valve & 14 & 32 & - & 100 & 45 \\
\hline & Pulmonic valve & - & - & - & 37 & 14 \\
\hline & Tricuspid valve & - & 19 & 3 & 64 & 17 \\
\hline & Ventricular myocardium & - & - & - & 49 & 46 \\
\hline
\end{tabular}

\section{APOE genotype}

APOE genotype data was available on a subset of 84 subjects, 46 with dementia and 38 controls. Although this information was not used to predict the groups, individuals carrying the $\epsilon 4$ allele were more common in the dementia groups. The summed memberships of individuals of each genotype are shown in Table 7. As individuals, the study subjects who exactly resembled a single profile contributed one to the size of the relevant profile and zero to the other profiles. Otherwise, the subject contributed a total of one to the sizes of the relevant profiles depending on the extent of resemblance. In contrast to results, Tables 4- 6 that predict frequencies for persons exactly like the group, Table 7 demonstrates that as individuals there was overlap of demented and nondemented subjects in the groups, not surprisingly given the many variables used to construct the groups, frequent comorbidity at advanced ages, and differences from individual to individual.

\section{DISCUSSION}

We investigated cardiovascular damage found for 84 demented and 60 nondemented subjects enrolled in the Bryan ADRC Rapid Autopsy Program. The subjects could be represented by five distinct latent groups based on detailed pathologic information. The late-onset $\mathrm{AD}$ groups, both male (IV) and female (V), had frequent heart valve damage, evidence of ischemic damage to the left ventricular myocardium, low BMI, and low organ weights no- tably including the thyroid gland. They did not have extensive atherosclerosis compared to control subjects without cancer (III), many of whom had possible AD. In particular, the female group $(\mathrm{V})$ having long $\mathrm{AD}$ duration had little atherosclerosis. Control subjects with cancer (II) had little atherosclerosis or valve damage. Instead, pulmonary edema and ascites were common. The early-onset AD group (I) had little cardiovascular damage, with normal organ weights despite low body weight.

The finding of mitral and aortic valve damage, and evidence of ischemic damage to the left ventricular myocardium for the $\mathrm{AD}$ groups, especially among men, is interesting. It is consistent with the hypothesis that brain hypoperfusion and microthrombi may contribute to the evolution of $\mathrm{AD}$ pathology or to the expression of dementia at an earlier stage in AD pathogenesis [40].

However, the $\mathrm{AD}$ groups (IV and V) were the oldest groups. Thus valve and myocardial damage might simply be age related and less rapidly fatal than extensive coronary atherosclerosis. Alternatively, the oldest cohorts in the sample may have valve damage resulting from rheumatic fever not treated with antibiotics. Assuming that mitral valve damage is related to rheumatic fever in the oldest subjects does not, however, rule out the possibility that it contributes to the expression of dementia by decreasing brain perfusion and, possibly, contributing to brain pathology.

In addition, the lack of an age-matched control group requires comment. Since aging is itself a risk factor for valvular disease, an age-matched control group would be 
TABle 6. Organ weights for each group. The model-based groups are defined by the probabilities response for the variables, here represented on a semiquantitative scale: “ ++++ " denotes the highest quartile of weight, while " +++ ," ",++ , and " + " denote the respectively lower quartiles.

\begin{tabular}{|c|c|c|c|c|c|}
\hline \multirow{2}{*}{ Organ } & \multicolumn{5}{|c|}{ Group } \\
\hline & I & II & III & IV & V \\
\hline Heart & + & +++ & ++++ & +++ & ++ \\
\hline Lungs & ++ & ++++ & +++ & ++ & + \\
\hline Liver & +++ & ++++ & ++++ & +++ & + \\
\hline Kidneys & +++ & +++ & ++++ & +++ & + \\
\hline Spleen & ++ & ++++ & ++++ & ++ & + \\
\hline Adrenals & +++ & ++++ & +++ & +++ & + \\
\hline Thyroid & +++ & ++++ & ++++ & +++ & + \\
\hline
\end{tabular}

TABLE 7. Distribution of subjects across the groups, subdivided according to dementia status and APOE genotype; $\epsilon 2 / 2$ and $\epsilon / 2 / 3$ were grouped with $\epsilon 3 / 3 ; \epsilon 2 / 4$ and $\epsilon 4 / 4$ were grouped with $\epsilon 3 / 4$. The sizes are the sums of the model $g_{i k}$ parameters, that is, the memberships of individuals in the groups, whole or partial.

\begin{tabular}{|c|c|c|c|c|c|c|c|}
\hline \multirow{2}{*}{\multicolumn{2}{|c|}{ Subjects }} & \multicolumn{6}{|c|}{ Group } \\
\hline & & I & II & III & IV & $\mathrm{V}$ & All \\
\hline \multicolumn{2}{|c|}{ Demented } & 30.9 & 2.3 & 8.5 & 19.7 & 22.6 & 84 \\
\hline \multicolumn{2}{|c|}{ Not demented } & 5.5 & 19.0 & 18.7 & 7.8 & 9.0 & 60 \\
\hline \multirow[t]{2}{*}{$\epsilon 3 / 3+$} & Demented & 4.0 & 0 & 2.0 & 3.9 & 5.0 & 15 \\
\hline & Normal & 2.4 & 9.1 & 8.6 & 2.2 & 3.6 & 26 \\
\hline \multirow[t]{2}{*}{$\epsilon 4 / 4$} & Demented & 12.3 & 1.0 & 3.2 & 8.2 & 6.2 & 31 \\
\hline & Normal & 1.6 & 3.5 & 3.8 & 1.5 & 1.5 & 11 \\
\hline \multicolumn{2}{|l|}{ Total } & 36.4 & 21.3 & 27.2 & 27.5 & 31.5 & 144 \\
\hline
\end{tabular}

required to fully examine the hypothesis that hypoperfusion contributes to dementia. Unfortunately, this was not possible in this small-human-population-based study. Rigorous analysis must await examination of a larger cohort.

Despite the caveats, the results on valve and myocardial damage are striking and the given frequent finding of the $\epsilon 4$ allele for $A P O E$ in the $\mathrm{AD}$ groups raises the possibility that ApoE directly damages these structures as it has been demonstrated to damage blood vessels $[42,43]$. Muscle actin in the arterioles is replaced by amyloid for $\epsilon 4 / 4+$ subjects to a much greater extent than for $\epsilon 3 / 3+$ subjects. Meyer et al [44] $(n=36)$ found hypertrophy of the left ventricle (uncommon in the Bryan ADRC sample) in 9 of $19(47 \%) \epsilon 3 / 4+\mathrm{AD}$ patients and only 1 of $11(9 \%)$ $\epsilon 3 / 3+$ patients $\left(\chi^{2} 2=3.8, \mathrm{df}=1, P=0.05\right)$. There were no statistically significant differences in the presence of stenotic changes or calcification in aortic or mitral valvulae in this small sample. The study results tend to suggest that the 5-fold worse prognosis following a diagnosis of heart disease or stroke at ages $85+$ for $\epsilon 4+$ persons may be due to impaired cerebrovascular function due to amyloid deposition [25]. Data presented here would also suggest that cardiovascular malfunction may be a contributing factor.

The study does not support the notion that extensive atherosclerosis is a risk factor for definite AD. Instead, subjects with extensive atherosclerosis died before a diagnosis of probable or definite $\mathrm{AD}$ could be made. The relatively low $\epsilon 4$ frequency for control subjects with extensive atherosclerosis was unexpected since the allele carries a modestly increased risk of coronary atherosclerosis $[13,14,15,16,17,44]$. There is also a small ecologic association between $\epsilon 4$ frequency and population rates of myocardial infarction in middle age $[45,46]$. Nevertheless the findings from this study are consistent with the lack of risk for heart disease and stroke for $\epsilon 4$ found in the Kungsholmen Project for cohort age of 75 and older [25].

Atherosclerosis may possibly at least partially reverse itself during the clinical progression of $\mathrm{AD}$ as weight is lost and food intake diminished. This explanation is supported to some extent by the fact that possible $\mathrm{AD}$ was common in the nondemented group with high heart weight and extensive atherosclerosis. So that atherosclerosis might be a common concomitant of early or preclinical $\mathrm{AD}$ but may not be found at the time of death many years later.

A strong feature of the study is that comparisons were made based on pathologic features and pathologically confirmed diagnoses. The data analytic approach was helpful in resolving the many items of information into a tractable number of distinct groups consistent with clinical experience, despite the relatively small sample 
size. For example, heart weight was highest for the group also having the most extensive athersosclerosis and lung weight was highest for the group also having pulmonary effusions and ascites.

In summary, extensive coronary atherosclerosis at autopsy was associated with death at earlier ages and limited AD pathology. Pathologically confirmed AD was not associated with extensive coronary atherosclerosis. Surprisingly, it was associated with mitral and aortic valve damage and damage to the ventricular myocardium.

\section{ACKNOWLEDGMENTS}

We thank the study subjects and their families who made the project possible. Hai Huang MD and Yi-Ping Pan MD were responsible for data abstraction. Financial support for the study was provided by Grants P50 AG05128 and R01AG07198 from the National Institute on Aging (USA), Glaxo Smith-Kline, and numerous small donations from patients and family members to the Joseph and Kathleen Bryan Alzheimer Disease Research Center.

\section{REFERENCES}

[1] Evans DA, Funkenstein HH, Albert MS, et al. Prevalence of Alzheimer's disease in a community population of older persons. Higher than previously reported. JAMA. 1989;262(18):2551-2556.

[2] Silver MH, Jilinskaia E, Perls TT. Cognitive functional status of age-confirmed centenarians in a population-based study. J Gerontol B Psychol Sci Soc Sci. 2001;56(3):P134-P140.

[3] Seshadri S, Wolf PA, Beiser A, et al. Lifetime risk of dementia and Alzheimer's disease The impact of mortality on risk estimates in the Framingham study. Neurology. 1997;49(6):1498-1504.

[4] Strittmatter WJ, Saunders AM, Schmechel D, et al. Apolipoprotein E: high-avidity binding to betaamyloid and increased frequency of type 4 allele in late-onset familial Alzheimer disease. Proc Nat Acad Sci USA. 1993;90(5):1977-1981.

[5] Saunders AM, Strittmatter WJ, Schmechel D, et al. Association of apolipoprotein E allele epsilon 4 with late-onset familial and sporadic Alzheimer's disease. Neurology. 1993;43(8):1467-1472.

[6] Corder EH, Saunders AM, Strittmatter WJ, et al. Gene dose of apolipoprotein E type 4 allele and the risk of Alzheimer's disease in late onset families. Science. 1993;261(5123):921-923.

[7] Lucotte G, Visvikis S, Leininger-Muler B, et al. Association of apolipoprotein E allele epsilon 4 with lateonset sporadic Alzheimer's disease. Am J Med Genet. 1994;54(3):286-288.

[8] Lucotte G, Aouizerate A, Gerard N, Turpin JC, Landais P. Allele doses of apolipoprotein E type epsilon 4 in sporadic late-onset Alzheimer's disease. Am J Med Genet. 1995;60(6):566-569.
[9] Lucotte G, Turpin JC, Landais P. Apolipoprotein Eepsilon 4 allele doses in late-onset Alzheimer's disease. Ann Neurol. 1994;36(4):681-682.

[10] Schmechel DE, Saunders AM, Strittmatter WJ, et al. Increased amyloid beta-peptide deposition in cerebral cortex as a consequence of apolipoprotein $\mathrm{E}$ genotype in late-onset Alzheimer disease. Proc Nat Acad Sci USA. 1993;90(20):9649-9653.

[11] Cumming AM, Robertson FW. Polymorphism at the apoprotein-E locus in relation to risk of coronary disease. Clin Genet. 1984;25(4):310-313.

[12] Davignon J, Gregg RE, Sing CF. Apolipoprotein E polymorphism and atherosclerosis. Arteriosclerosis. 1988;8(1):1-21.

[13] Laakso M, Kesaniemi A, Kervinen K, Jauhiainen M, Pyorala K. Relation of coronary heart disease and apolipoprotein $\mathrm{E}$ phenotype in patients with non-insulin dependent diabetes. BMJ. 1991;303(6811):1159-1162.

[14] van Bockxmeer FM, Mamotte CD. Apolipoprotein epsilon 4 homozygosity in young men with coronary heart disease. Lancet. 1992;340(8824):879-880.

[15] Eichner JE, Kuller LH, Orchard TJ, et al. Relation of apolipoprotein E phenotype to myocardial infarction and mortality from coronary artery disease. Am J Cardiol. 1993;71(2):160-165.

[16] Stengard JH, Zerba KE, Pekkanen J, Ehnholm C, Nissinen A, Sing CF. Apolipoprotein E polymorphism predicts death from coronary heart disease in a longitudinal study of elderly Finnish men. Circulation. 1995;91(2):265-269.

[17] Hallman DM, Boerwinkle E, Saha N, et al. The apolipoprotein E polymorphism: a comparison of allele frequencies and effects in nine populations. Am J Hum Genet. 1991;49(2):338-349.

[18] Wilson PW. Established risk factors and coronary artery disease: the Framingham study. Am J Hypertens. 1994;7(pt 2):7S-12S.

[19] Gerdes LU, Gerdes C, Kervinen K, et al. The apolipoprotein epsilon 4 allele determines prognosis and the effect on prognosis of simvastatin in survivors of myocardial infarction: a substudy of the Scandinavian simvastatin survival study. Circulation. 2000;101(12):1366-1371.

[20] Slooter AJ, Tang MX, van Duijn CM, et al. Apolipoprotein E epsilon 4 and the risk of dementia with stroke. A population-based investigation. JAMA. 1997;277(10):818-821.

[21] Goldstein LB, Vitek MP, Dawson H, Bullman S. Expression of the apolipoprotein $\mathrm{E}$ gene does not affect motor recovery after sensorimotor cortex injury in the mouse. Neuroscience. 2000;99(4):705-710.

[22] Pasquier F, Henon H, Leys D. Risk factors and mechanisms of post-stroke dementia. Rev Neurol (Paris). 1999;155(9):749-753.

[23] Ervin JF, Pannell C, Szymanski M, Welsh-Bohmer K, Schmechel DE, Hulette CM. Vascular smooth muscle actin is reduced in Alzheimer disease brain: 
a quantitative analysis. J Neuropathol Exp Neurol. 2004;63(7):735-741.

[24] Corder EH, Basun H, Fratiglioni L, et al. Inherited frailty. ApoE alleles determine survival after a diagnosis of heart disease or stroke at ages 85+. Ann N Y Acad Sci. 2000;908:295-298.

[25] Schachter F, Faure-Delanef L, Guenot F, et al. Genetic associations with human longevity at the APOE and ACE loci. Nat Genet. 1994;6(1):29-32.

[26] Aronson MK, Ooi WL, Morgenstern $\mathrm{H}$, et al. Women, myocardial infarction, and dementia in the very old. Neurology. 1990;40(7):1102-1106.

[27] Breteler MM, Claus JJ, Grobbee DE, Hofman A. Cardiovascular disease and distribution of cognitive function in elderly people: the Rotterdam study. BMJ. 1994;308(6944):1604-1608.

[28] Sparks DL, Scheff SW, Liu H, Landers TM, Coyne CM, Hunsaker JC 3rd. Increased incidence of neurofibrillary tangles (NFT) in nondemented individuals with hypertension. J Neurol Sci. 1995;131(2):162-169.

[29] Prince M, Cullen M, Mann A. Risk factors for Alzheimer's disease and dementia: a case-control study based on the MRC elderly hypertension trial. Neurology. 1994;44(1):97-104.

[30] Launer LJ, Masaki K, Petrovitch H, Foley D, Havlik RJ. The association between midlife blood pressure levels and late-life cognitive function. The Honolulu-Asia aging study. JAMA. 1995;274(23):1846-1851.

[31] Skoog I, Lernfelt B, Landahl S, et al. 15-year longitudinal study of blood pressure and dementia. Lancet. 1996;347(9009):1141-1145.

[32] Guo Z, Viitanen M, Winblad B, Fratiglioni L. Low blood pressure and incidence of dementia in a very old sample: dependent on initial cognition. J Am Geriatr Soc. 1999;47(6):723-726.

[33] Hofman A, Ott A, Breteler MM, et al. Atherosclerosis, apolipoprotein E, and prevalence of dementia and Alzheimer's disease in the Rotterdam study. Lancet. 1997;349(9046):151-154.

[34] Lass P, Buscombe JR, Harber M, Davenport A, Hilson AJ. Cognitive impairment in patients with renal failure is associated with multiple-infarct dementia. Clin Nucl Med. 1999;24(8):561-565.

[35] Irina A, Seppo H, Arto M, Paavo R Sr, Hilkka S. $\beta$ amyloid load is not influenced by the severity of cardiovascular disease in aged and demented patients. Stroke. 1999;30:613-618.

[36] Hulette CM, Welsh-Bohmer KA, Crain B, Szymanski $\mathrm{MH}$, Sinclaire NO, Roses AD. Rapid brain autopsy. The Joseph and Kathleen Bryan Alzheimer's Disease Research Center experience. Arch Pathol Lab Med. 1997;121(6):615-618.

[37] Brown P, Wolff A, Gajdusek DC. A simple and effective method for inactivating virus infectivity in formalin-fixed tissue samples from patients with Creutzfeldt-Jakob disease. Neurology.
1990;40(6):887-890.

[38] Centers for Disease Control. Agent summary statement for human immunodeficiency virus and report on laboratory-acquired infection with human immunodeficiency virus. MMWR. 1988;37:S5.

[39] Manton KG, Woodbury MA, Tolley HD. Statistical Applications Using Fuzzy Sets. New York, NY:John Wiley \& Sons; 1994.

[40] Manton KG, Stallard E, Corder LS. The dynamics of dimensions of age-related disability 1982 to 1994 in the US elderly population. J Gerontol A Biol Sci Med Sci. 1998;53(1):B59-B70.

[41] Akaike H. Information theory and an extension of the maximum likelihood principle. In: Proc 2nd International Symposium on Information Theory. Budapest, Hungary:Akademiai Kiado; 1973:267-281.

[42] Hulette CM, Welsh-Bohmer KA, Murray MG, Saunders AM, Mash DC, McIntyre LM. Neuropathological and neuropsychological changes in "normal" aging: evidence for preclinical Alzheimer disease in cognitively normal individuals. $J$ Neuropathol Exp Neurol. 1998;57(12):1168-1174.

[43] Kosunen O, Talasniemi S, Lehtovirta M, et al. Relation of coronary atherosclerosis and apolipoprotein E genotypes in Alzheimer patients. Stroke. 1995;26(5):743-748.

[44] Meyer JS, Rauch G, Rauch RA, Haque A. Risk factors for cerebral hypoperfusion, mild cognitive impairment, and dementia. Neurobiol Aging. 2000;21(2):161-169.

[45] Otto CM, Lind BK, Kitzman DW, Gersh BJ, Siscovick DS. Association of aortic-valve sclerosis with cardiovascular mortality and morbidity in the elderly. N Engl J Med. 1999;341(3):142-147.

[46] Stengard JH, Pekkanen J, Sulkava R, Ehnholm C, Erkinjuntti T, Nissinen A. Apolipoprotein E polymorphism, Alzheimer's disease and vascular dementia among elderly Finnish men. Acta Neurol Scand. 1995;92(4):297-298. 

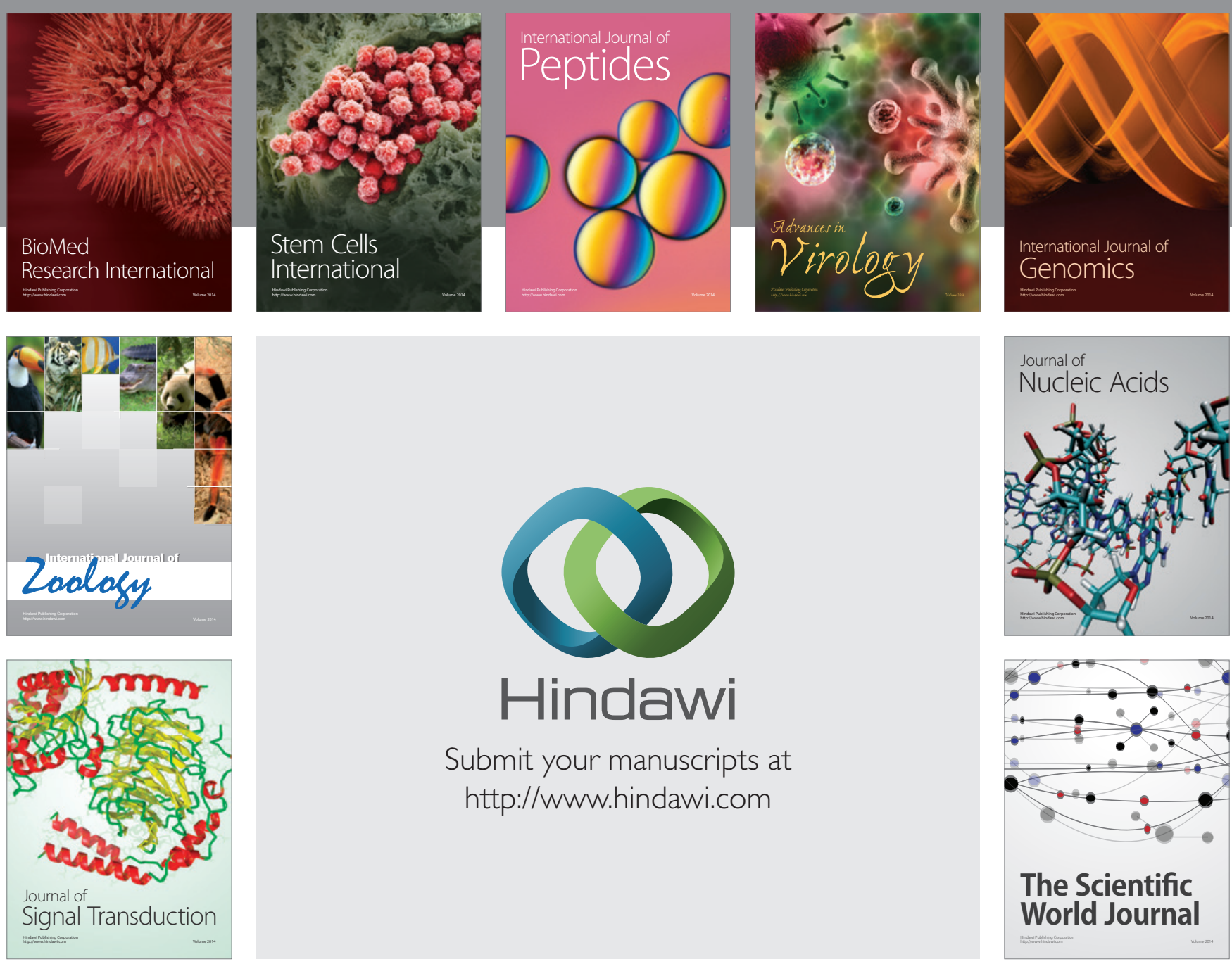

Submit your manuscripts at

http://www.hindawi.com
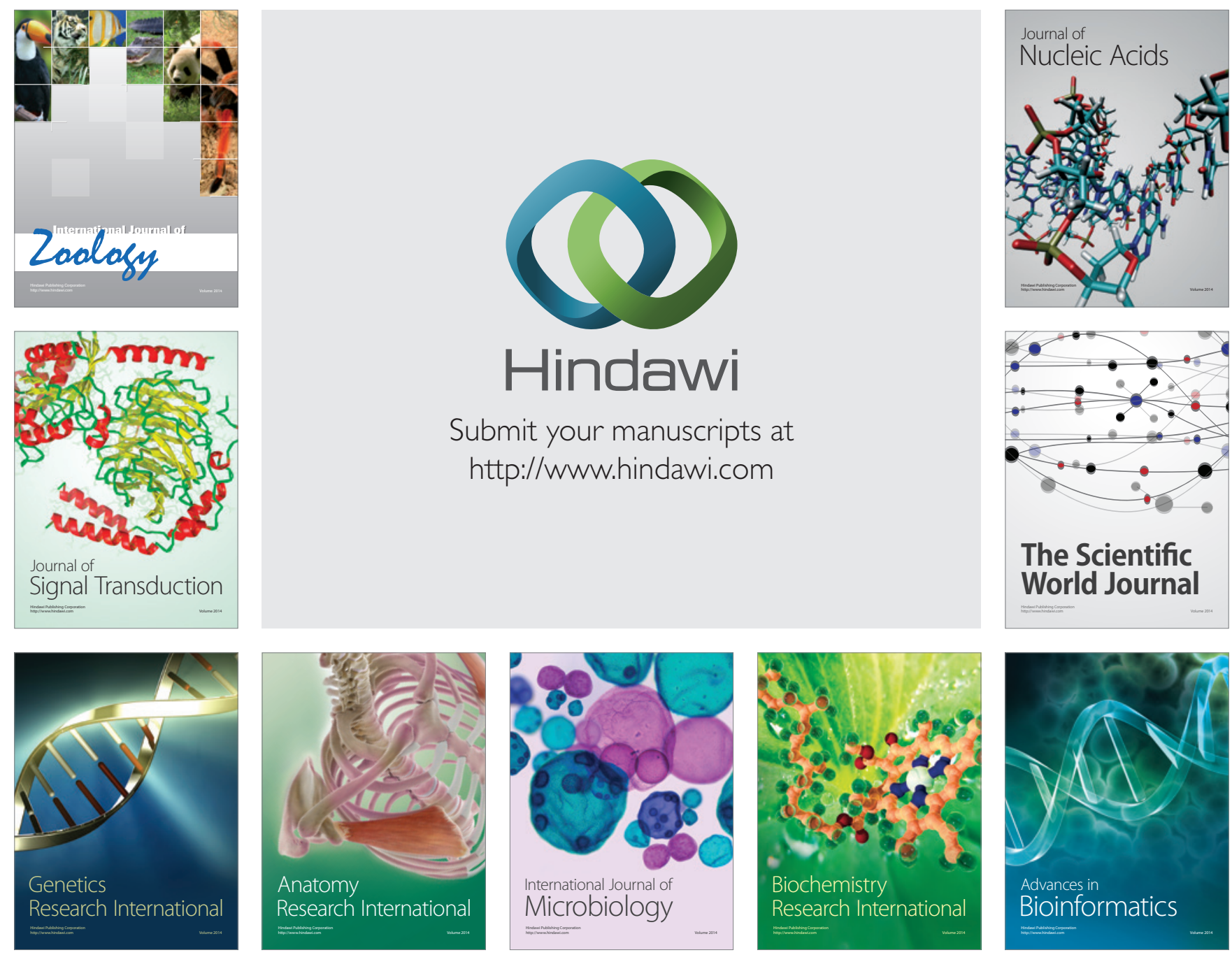

The Scientific World Journal
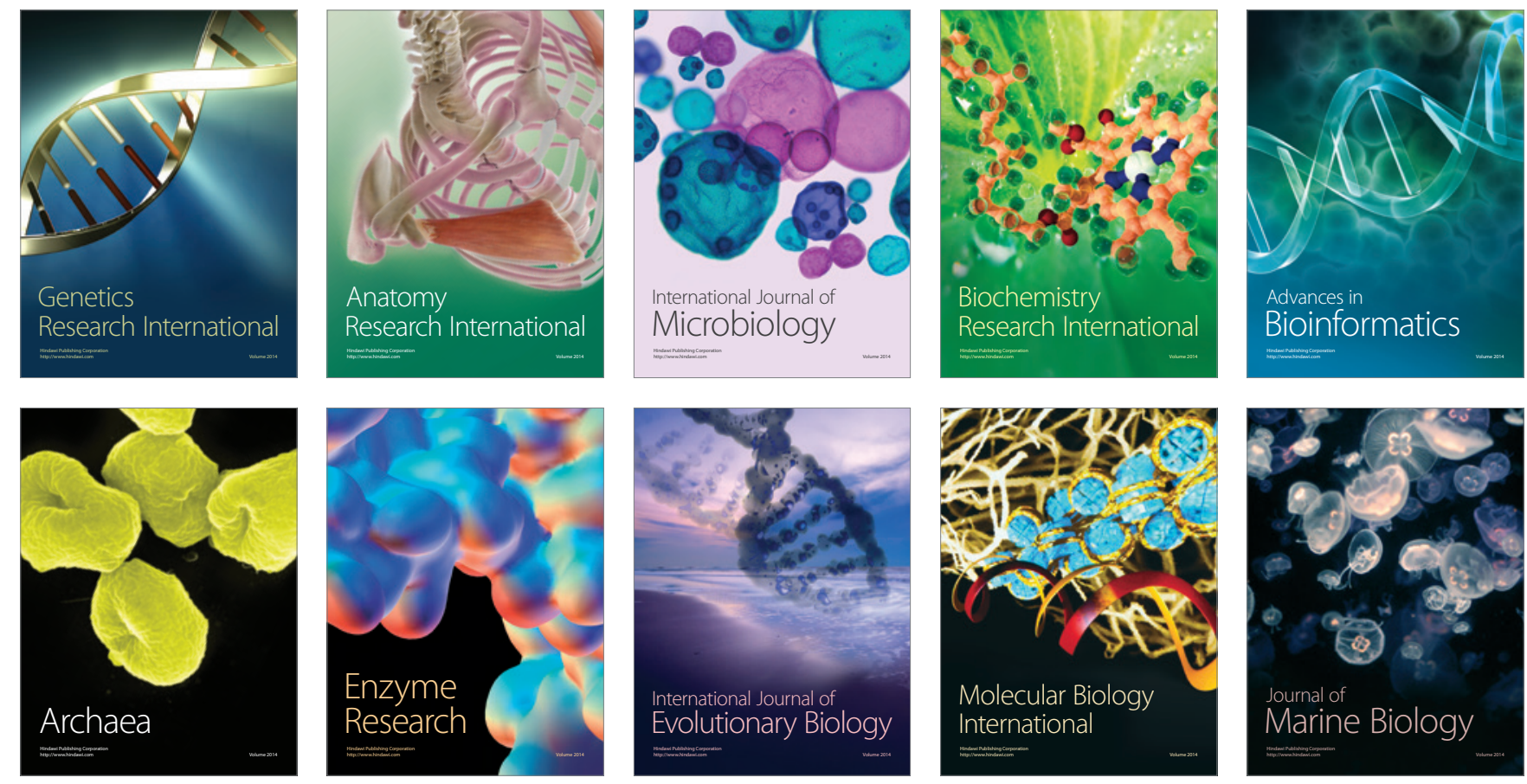